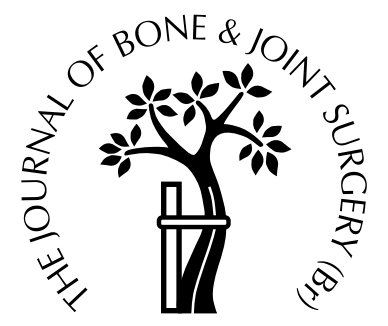

\title{
Fractures of the glenoid treated by operation
}

\author{
A 5- TO 23-YEAR FOLLOW-UP OF 22 CASES
}

P. Schandelmaier, M. Blauth, C. Schneider, C. Krettek

From the Leopold-Franzens Universität, Innsbruck, Austria

W e describe the results after open reduction and internal fixation of 22 consecutive displaced fractures of the glenoid with a mean follow-up of ten years. A posterior approach was used in 16 patients and an anterior in six, the approach being chosen according to the Ideberg classification of the fractures. The fixation failed in two patients, one of whom required a further operation. There were two cases of deep infection.

At follow-up the median Constant score was 94\% (mean 79\%, range 17 to 100). The score was less than $50 \%$ in four patients, including the two who became infected. A further two had an associated complete palsy of the brachial plexus.

J Bone Joint Surg [Br] 2002;84-B:173-7.

Received 11 April 2001; Accepted after revision 3 August 2001

Fractures of the scapula are uncommon and most can be treated conservatively. ${ }^{1-3}$ Open reduction and internal fixation is accepted as the treatment of choice for displaced intra-articular fractures in most anatomical sites. However, the place of surgery in the management of fractures of the glenoid remains unclear. They are often associated with other injuries which take priority and may preclude fixation. ${ }^{1,3-12}$ Several authors have reported, however, that for many displaced fractures of the glenoid, the best results may be obtained with open reduction and fixation. 3 ,6-9,13-17

We have therefore carried out a retrospective study to assess the outcome after the surgical management of such fractures.

P. Schandelmaier, MD, Associate Professor

M. Blauth, MD, Professor and Chairman

Department of Trauma, Leopold-Franzens Universität, Anichstrasse 35, A6020 Innsbruck, Austria.

C. Schneider, MD, Consultant Orthopaedic Surgeon

C. Krettek, MD, Professor and Chairman

Department of Trauma, Hannover Medical School, Neuberg Strasse 1, 30623 Hannover, Germany.

Correspondence should be sent to Professor P. Schandelmaier.

C2002 British Editorial Society of Bone and Joint Surgery 0301-620X/02/212357\$2.00

\section{Patients and Methods}

We identified 438 fractures of the scapula treated between 1974 and 1994 of which 101 involved the glenoid. These were classified according to the system of Ideberg (Fig. 1). ${ }^{18}$ There were 74 type-I fractures involving avulsion of the rim, and 22 type-II to type-V. Only the latter were included in our study. Nine patients had a type-II, four a type-III, one a typeIV and eight a type- $\mathrm{V}$ fracture (Fig. 1).

The mean age of the patients was 34 years (16 to 68). Thirteen had been injured in road-traffic accidents and six in a fall. In two there was an associated complete palsy of the brachial plexus and in one an incomplete lesion of the upper part. Six patients had additional fractures in the same limb. Three had a 'floating shoulder'. In nine, the neck of the scapula had been fractured and in 11 the body. Five had a fracture of the acromion and two a fracture of the coracoid process. Other injuries included fractures of the ribs in nine patients, spinal fractures in three and fractures of the lower limb in three.

The standard preoperative radiological evaluation included a $40^{\circ}$ posterior oblique, a $60^{\circ}$ anterior oblique and an axillary view. If the fracture was not clearly visualised on plain radiographs, anteroposterior tomography and/or CT was used to define further the fragments of the fracture and the displacement. The residual displacement seen on intraand postoperative radiographs was recorded.

Operative procedure. Operation was undertaken within one week of injury. An anterior approach was used in six of the nine patients with a type-II fracture and a posterior approach in the remaining three and in all the others (Fig. 2). The intra- and extra-articular aspects of the fracture were manipulated under direct vision and anatomical reduction was accomplished in 18 fractures. The postoperative radiographs showed a step of less than $2 \mathrm{~mm}$ in 18 fractures, and of between 2 and $4 \mathrm{~mm}$ in four. The quality of the postoperative radiographs was usually poor, and during this time postoperative CT was not used to assess the reduction. In seven patients only screws were used, in nine one plate, in five two plates and in one four plates. One-third tibular plates were used in nine (Fig. 3), $3.5 \mathrm{~mm}$ small fragment plates in three and $3.5 \mathrm{~mm}$ reconstruction plates in three (Fig. 4). Because of the extended period of the study 15 surgeons were involved. 

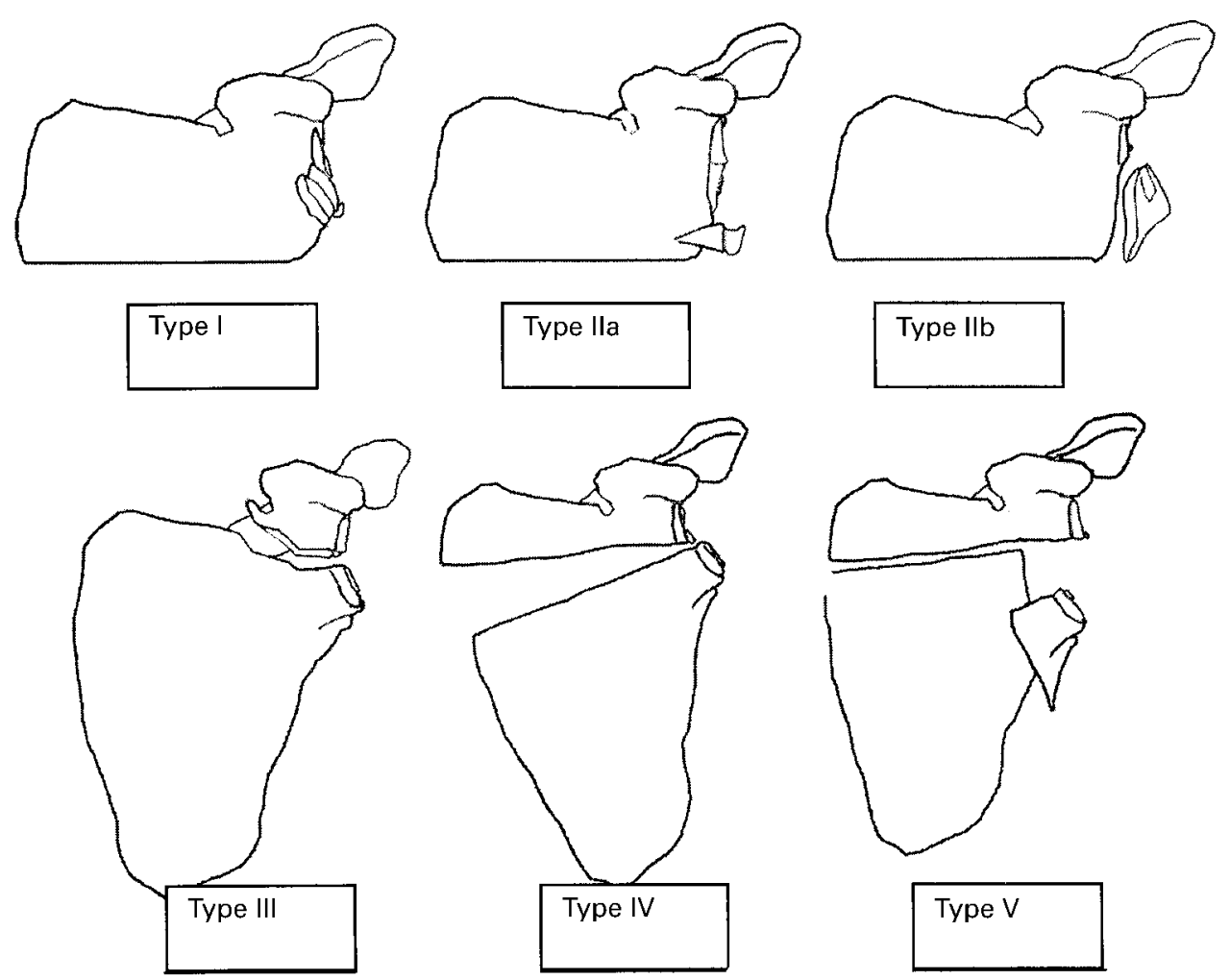

Type Ila

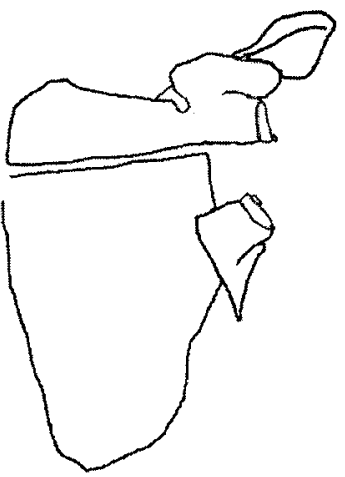

Type V

Fig. 1

Diagram showing the Ideberg classification ${ }^{18}$ of fractures of the glenoid.

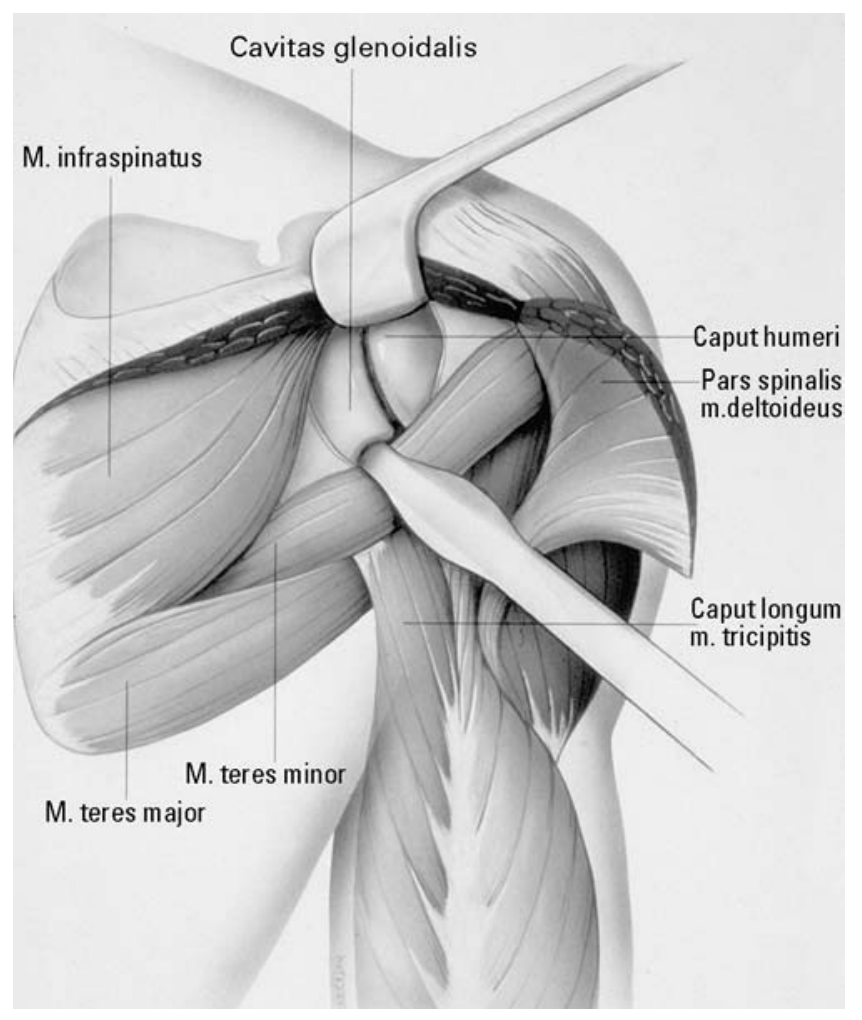

Fig. 2

Diagram showing the posterior approach to the glenoid fossa.
On the second day after operation range-of-motion and isometric exercises were started. Two to three months later the use of elastic strapping for strengthening exercises was added to the rehabilitation programme which was modified during the course of the study. The mean follow-up was for ten years (5 to 23). The patients completed a detailed questionnaire and clinical examination was undertaken. The outcome was assessed using the Constant and Murley score. ${ }^{19}$ Patients who were unable to attend for follow-up were assessed at home by one of the authors (CS) and in eight patients radiography was arranged locally. Post-traumatic radiological degenerative changes were recorded.

\section{Results}

The mean length of stay in hospital was 15 days (5 to 33) and the mean operating time was 175 minutes (100 to 375).

Follow-up. The outcome of the 22 fractures was determined using the Constant and Murley score ${ }^{19}$ (Fig. 5). Both shoulders were assessed and the score on the injured side was given as a percentage of that on the uninjured side. The median score was $94 \%$ (mean $79 \%$, range 17 to 100). The median score for strength was $25 / 25$ (mean 20 , range 0 to 25 ) and that for pain $13 / 15$ (mean 12 , range 5 to 15 ). The median functional score was 20/20 (mean 16, range 0 to 20). The mean range of active abduction of the shoulder 


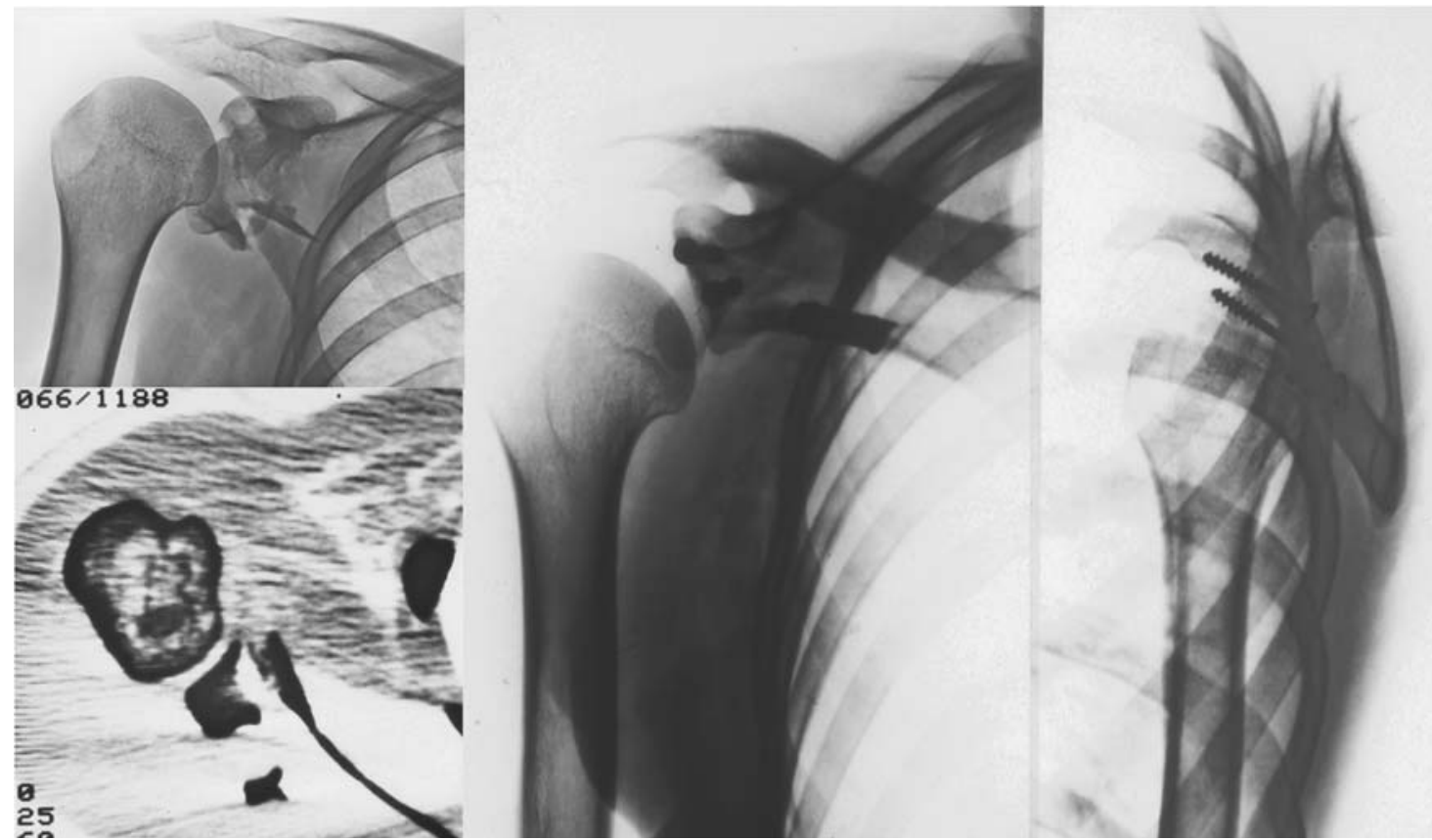

Fig. 3

Case 9. Radiographs and CT showing screw and plate fixation in a type-V fracture.

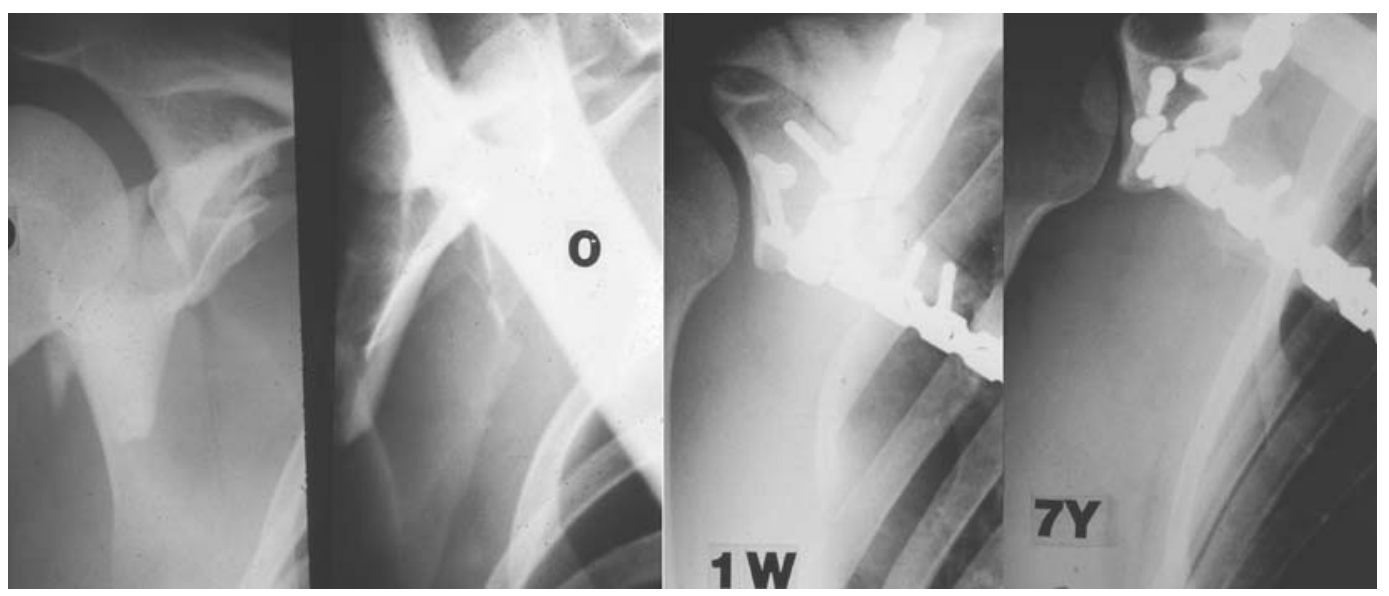

Fig. 4

Case 8. Radiographs showing screw and plate fixation in a type- $\mathrm{V}$ fracture.

was $148^{\circ}$ (20 to 180 ), the mean range of flexion $146^{\circ}$ (20 to 180 ) and the mean range of external rotation $40^{\circ}$ (0 to 100).

There was radiological evidence of degenerative changes in five patients, one of whom with a follow-up score of $100 \%$ had degenerative disease before the fracture, and two who had a deep infection (follow-up score 27\%, 62\%). One of the remaining patients had a postoperative step of $3 \mathrm{~mm}$ and the other an anatomical reduction. These had functional scores of $98 \%$ and $100 \%$. The implants were not removed routinely. Except for the two cases of complete brachial plexus palsy who had a follow-up score of $17 \%$, no other lesions were detected at review.
Complications. A superficial infection settled with antibiotics after operation in one patient whose score at final follow-up was $98 \%$. In one patient, with delayed healing because of infection, one of the four plates broke; the fracture united at 3.5 months and the final follow-up score after debridement and removal of the implant was $27 \%$. Deep infection developed in one patient 12 months after operation and Proteus vulgaris was cultured; the follow-up score was $62 \%$. One patient with stiffness of the shoulder at six weeks underwent manipulation under anaesthesia with a follow-up score of $81 \%$. Another developed impingement and was treated by arthroscopic subacromial decompression seven years after the injury; the follow-up score was 


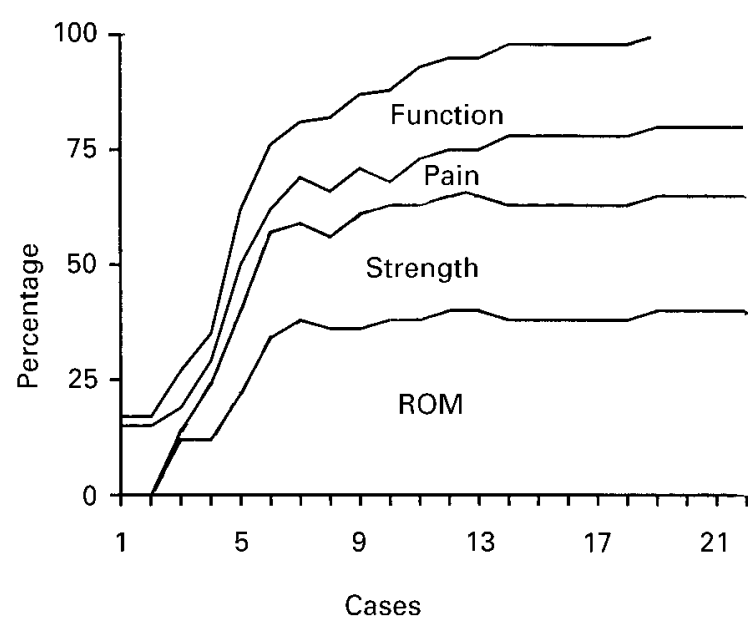

Fig. 5

The results according to the Constant and Murley score. ${ }^{19}$

$35 \%$. In one patient seen 17 years after injury, the one-third tubular plate was broken; the score was $93 \%$. The position of the fracture achieved at operation was maintained in all patients except one.

\section{Discussion}

Conservative treatment is generally recommended for scapular fractures and operation is rarely required. ${ }^{3,8,20}$ Several authors have, however, recommended operative treatment for displaced fractures, in order to reduce the incidence of post-traumatic arthritis of the shoulder. $3,7,8,13,16,21$ The results after open reduction and internal fixation of displaced intra-articular fractures of the glenoid have been reported. 3,7,8,13,21,22 Aulicino et $\mathrm{al}^{3}$ described the findings in two patients who had been followed for two and three years after operation; both had an excellent result. Hardegger et $\mathrm{al}^{8}$ have recorded the largest series of surgically-treated scapular fractures which included 12 involving the glenoid. They recommended reduction and fixation of incongruent fractures of the glenoid, but the results for this specific type of fracture were not separated from those of the group as a whole. Aston and Gregory ${ }^{4}$ described three operativelytreated fractures of the glenoid which had been associated with dislocation of the shoulder. Kavanagh et al $^{9}$ described ten fractures of the glenoid fixed through a posterior approach. Although the patients were satisfied with the outcome no scoring system was used and the follow-up times were not reported. The largest series of fractures of the glenoid was reported by Leung et $\mathrm{al}^{14}$ with a mean follow-up of 30.5 months. There was an excellent result in three and a good result in 11, using their own scoring system. They did not report complications related to the initial operation. There is very little information available about the outcome after conservative treatment of displaced fractures of the glenoid. Wilber and Evans ${ }^{20}$ described the conservative management of three displaced fractures of the glenoid from a series of 52 scapular fractures. They did not, however, record the displacement at the time of injury or after union of the fracture. Two patients had a fair result, with slight pain and loss of movement of less than $25 \%$; the third had a poor result with moderate pain and loss of both flexion and abduction of the shoulder of more than $25 \%$. These authors suggested immobilisation of the arm in abduction, followed by physiotherapy, as a more aggressive form of treatment for intra-articular fractures of the glenoid.

Our group of 22 displaced fractures of the glenoid is, to our knowledge, the largest series from a single centre. The indication for surgery was intra-articular displacement of more than $5 \mathrm{~mm}$. The mean follow-up was for ten years with a minimum of five. We did not find a deterioration of the functional result with time. The use of the Constant and Murley score ${ }^{19}$ is recommended by the European Society of Shoulder and Elbow Surgeons. The results of operatively-treated fractures of the glenoid were good if there was no associated complete brachial plexus palsy and if postoperative complications were avoided. With brachial plexus palsy the outcome after operative treatment was determined by the neurological recovery.

Open reduction and fixation can give good results for patients with displacement of the glenoid fossa as with other articular fractures. Additional factors such as polytrauma, brachial plexus injury, and the general condition of the patient should be taken into consideration when undertaking operative treatment. The Ideberg classification ${ }^{18}$ is useful when planning the surgical approach. If the postoperative course is uneventful, excellent and good results can be expected.

No benefits in any form have been received or will be received from a commercial party related directly or indirectly to the subject of this article.

\section{References}

1. Ideberg R, Grevsten S, Larsson S. Epidemiology of scapular fractures: incidence and classification of 338 fractures. Acta Orthop Scand 1995;66:395-7.

2. Imatani RJ. Fractures of the scapula: a review of 53 cases. J Trauma 1975;15:473-8.

3. Aulicino PL, Reinert C, Kornberg M, Williamson S. Displaced intra-articular glenoid fractures treated by open reduction and internal fixation. J Trauma 1986;26:1137-41.

4. Aston JW Jr, Gregory CF. Dislocation of the shoulder with significant fracture of the glenoid. $J$ Bone Joint Surg [Am] 1973;55-A:1531-3.

5. Bauer G, Fleischmann W, Dussler E. Displaced scapular fractures: indication and long-term results of open reduction and internal fixation. Arch Orthop Trauma Surg 1995;114:215-9.

6. Euler E, Habermeyer P, Kohler W, Schweiberer L. Scapula fractures: classification and differential therapy. Orthopäde 1992;21:158-62.

7. Goss TP. Fractures of the glenoid cavity. J Bone Joint Surg [Am] 1992;74-A:299-305.

8. Hardegger FH, Simpson LA, Weber BG. The operative treatment of scapular fractures. J Bone Joint Surg [Br] 1984;66-B:725-31. 
9. Kavanagh BF, Bradway JK, Cofield RH. Open reduction and internal fixation of displaced intra-articular fractures of the glenoid fossa. J Bone Joint Surg [Am] 1993;75-A:479-84.

10. Thompson DA, Flynn TC, Miller PW, Fischer RP. The significance of scapular fractures. J Trauma 1985;25:974-7.

11. McGinnis M, Denton JR. Fractures of the scapula: a retrospective study of 40 fractured scapulae. J Trauma 1989;29:1488-93.

12. Zdravkovic D, Damholt VV. Comminuted and severely displaced fractures of the scapula. Acta Orthop Scand 1974;45:60-5.

13. Fleischmann W, Kinzl L. Philosophy of osteosynthesis in shoulder fractures. Orthopedics 1993;16:59-63.

14. Leung KS, Lam TP, Poon KM. Operative treatment of displaced intra-articular glenoid fractures. Injury 1993;24:324-8.

15. Sinha J, Miller AJ. Fixation of fractures of the glenoid rim. Injury 1992;23:418-9.

16. Tscherne H, Christ M. Konservative und Operative Therapie der Schulterblattbrüche. Hefte Unfallheilkd 1975;126:52-9.
17. Mayo KA, Benirschke SK, Mast JW. Displaced fractures of the glenoid fossa: results of open reduction and internal fixation. Clin Orthop 1998;347:122-30.

18. Ideberg R. Fractures of the scapula involving the glenoid fossa. In: Bateman JE, Welsh RP, eds. Surgery of the shoulder. Philadelphia: Decker, 1984:63-6.

19. Constant CR, Murley AHG. A clinical method of functional assessment of the shoulder. Clin Orthop 1987;214:160-4.

20. Wilber MC, Evans EB. Fractures of the scapula: an analysis of forty cases and review of the literature. J Bone Joint Surg [Am] 1977;59-A:358-62.

21. Terbruggen D, Muller J, Skutella E. Osteosynthesis of scapular fractures within the scope of multiple injuries of the shoulder girdle. Hefte Unfallheilk 1975;126:62-3.

22. Herscovici D Jr, Fiennes AG, Allgower M, Ruedi TP. The floating shoulder: ipsilateral clavicle and scapular neck fractures. J Bone Joint Surg [Br] 1992;74-B:362-4. 